\title{
Social Media Perception Affecting the Business of PTT Public Company Limited
}

\author{
Achara Chatchalermpol, Wuttipong Pongsuwan, Leelavadee Vajropala \\ Shinawatra International University, Bangkok, Thailand \\ 57425005-6@st.siu.ac.th,wuttipong.p@siu.ac.th, leelavadee@hotmail.com
}

\begin{abstract}
The social media perception affecting the business of PTT Public Company Limited (PTT) aims for three purposes. Firstly, to study customers' behavior via social media's perception. Secondly, to study interaction between social media and customers. Finally, to study the impact of any information channels via social media that affects to user of products, related services, and company's images. Social media has been played a vital role rapidly in communication and transferring a huge of information in the manner of videos and contents widespread, which persuade many companies to promote their company via social media to acquire customers' attentions even related services including the public relation for the company's image. PTT has adjusted to a new era of social media comply with organizational communication plan. However, social media has affects both positive and negative impact at the same time. The company is rumored a negative issue in society and triggered by social media such as FB's page "Pay back PTT" is a web page for whom anti PTT. The company must handle these impact of negative information that can transfer to the customer of company in term of goods and service or any attitude that affect to company's image after receiving any information that derived from social media. Therefore, it is necessary to manage social media contents to create two ways of understanding about any issues and also prevent social media disaster from company's communication in term of attitude, image and decision making process to consume goods and service. This study is to provide recommended policy for PTT to improve their communication process and enhance trust for customer and investor in the future.
\end{abstract}

Keywords: Social Media, Perception, Image, Brand, Reputation, Energy Market, Stakeholder, Influence, Product, Service, Communication, Facebook, Twitter, Line, Application, Interpretation, In-depth interview

\section{Introduction}

Social media and social networking has become a new marketing tool for business where anyone can share opinions and attitudes for their services and any related information (Dincer and Dincer, 2012). Currently, social media has changed and updated over time in the various contexts of technology development, which influenced human behavior in these days whether communication via the internet or search engine to seek any useful information in daily life, including e-commerce and entertainment activities (Erdogmus, and Cicek, 2012). According to Chi (2011) defined that social media as marketing tools "to connect with brands and consumer, while offering a social interaction and social networking." The main strategic marketing in the current of many companies focuses on customer relation management and public relations to promote brands via TVs, and social media, which initiate brand awareness, and stimulate customers' demand step by step (Khuong and Tram, 2015). Any person who perceives information via TVs, and social media might be covered advertisement of products. To perceive information appropriately, it depends on factor influencing perception which is classified into two types that are external and internal factors. The external factors are such as intensively and size, repetition, contrast, movement. The internal factors are such as motive, expectancy, mood, attitude, and interest. Shiffman and Kanuk (2009, as cited in Camelia, 2012) claimed that these perceptions may cause positive and negative consequences transferring of information and presentation via social media which require carefulness of transferring information correctly and two ways communication that creates an understanding between sender and receiver. From the survey of data related to social media, it is found that the categories of data composed of four types that are popular for user in the nature of providing information which are information about jobs requirement, investor relations, corporate social responsibility, and organizational business communication (Phaisarn, 2016) as in figure 1. 
Figure 1: Social Media for providing information

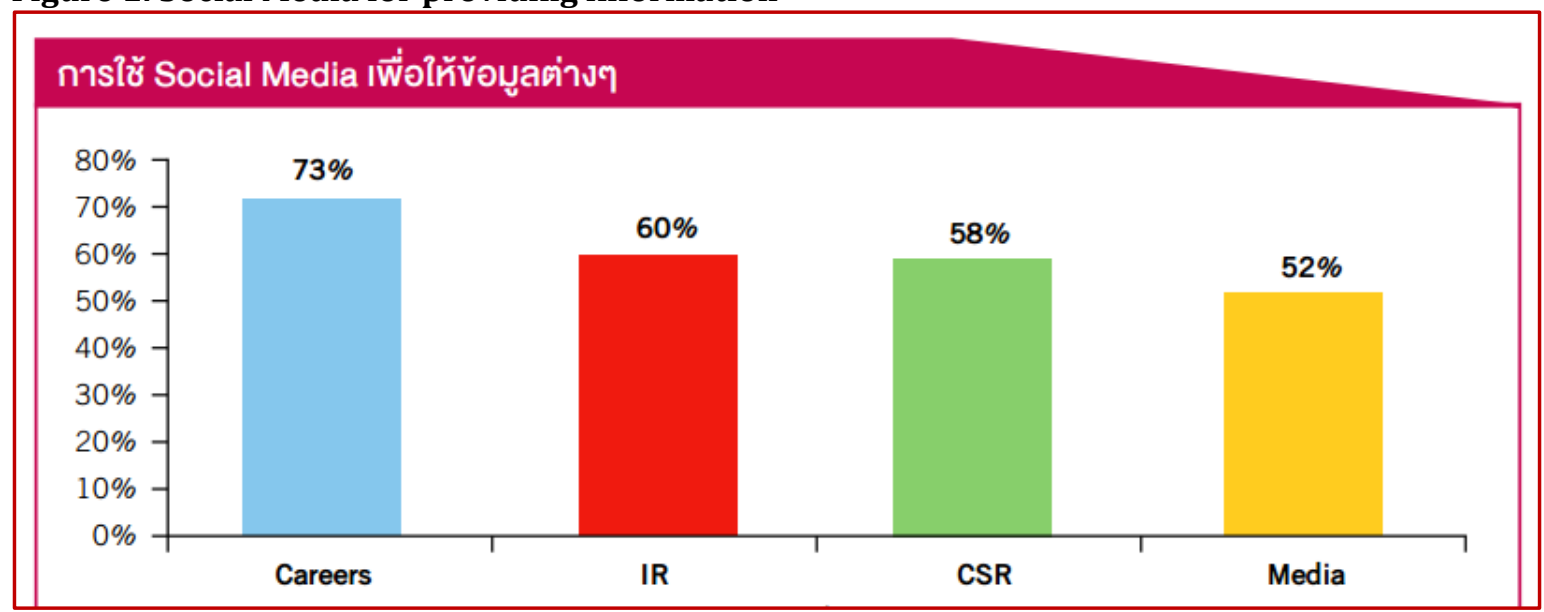

Ref: Phaisarn, J. (2016) "Social Media and Investor Relations"

The company need develop and adapt to use information from social media in parallel with business growth (Tugrul, 2014). IT is the potential to build relationship between organization and customers which bring to profit, images, reputation, brand loyalty, and so on (Dincer \& Dincer, 2012). It is the cooperation of the communication technology and the corporate communication to create social media of which the budget, efficiency, customer satisfaction are considered (Murat, Dugyu and Nil, 2015). PTT is a national energy company of Thailand and also registered in stock exchange of Thailand (SET). PTT has been developing marketing communication into the modern age as the same as the age of social media. The company has adjusted the social media in term of communications both internal and external and also had invested a portion of an organization's technology including communication, with a budget of $3 \%$ of net profit per year to developed public relations, advertisement, marketing or customer services and so on by having an affiliate called PTT ICT to response for company's communication technologies. As social media plays a vital role, PTT implements it in the manner of advertisement, public relations to promote products and services for example Green Service for environmental conservation and to deal with social media disaster, edit news correctly and spread the information widely and quickly to the world. Moreover, the development of data communication through social media and the study of customer perception channel on social media have an impact on the social structure of customer and company. It contributes to the development and gets in touch with the target group via the network that even more interesting (Dincer and Dincer, 2012).

\section{Literature Review}

Perception Process: Perception is a communication method that how to perceive information accidentally, or intentionally, or direct experience or indirect one to analyze and interpret information and evaluated information that receives from selective information. George \& Michael (1993, as cited in Yun and Cho, 2014) claimed that perception procedure composed of four categories as following;

- Selective exposure is a method of customers wants to receive information or not .For example, customers may read or look at the advertisement before making decision process .Which advertisement is not their interest, they ignore it .Therefore, the customer just open only for their want to receive .

- Selective attention is a method of focus on information while ignoring others stimulator .

- Selective comprehension is consumer selective method any information and interprets base on their attitude, believe, motive, and self-experience .Sometimes, it may cause misunderstand and inconsistent accordance sender's means.

- Selective retention is a perception of advertisement or information that heard, seen, or read through the process of interpretation or comprehension. The consumer will remember only specific or outstanding base on only their interest . 
Figure 2: Perception process by George \& Michael

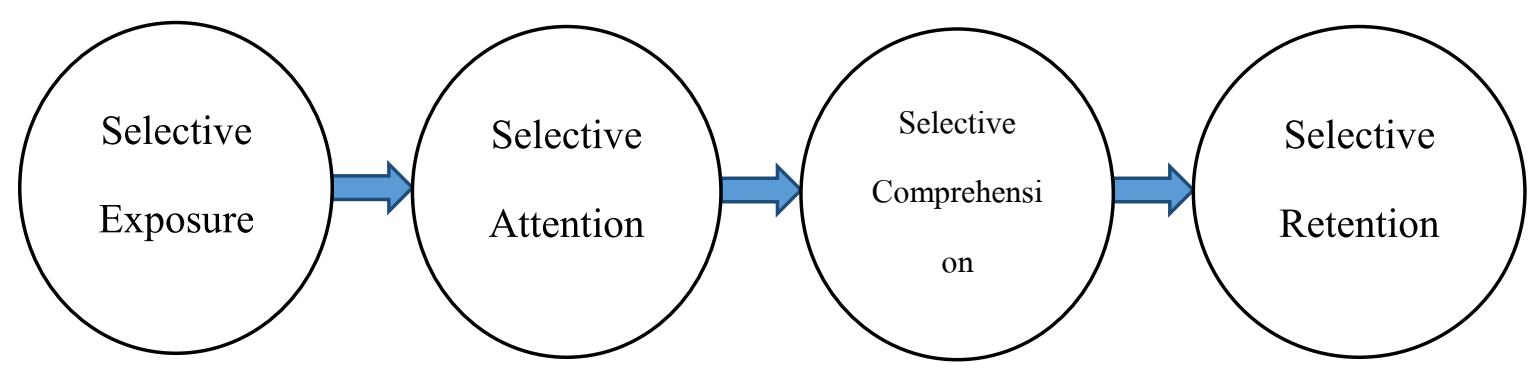

Ref. George \& Michael (1993, as cited in Yun and Cho, 2014)

The Perception Image of Brand and Service: Brand perception is a perception of brand quality or products. Brand perception of the consumer can measure from consumers' attitude towards the brand. How consumer perceive marketing via brand, which it thoughts related to (CRM: Customer Relationship Management) towards consumers' perception. It found that brand equity measurement as an important method for brands to measure how brands believe and influence in the market share. Therefore, there are attempts to research and develop in brand measurement in many ways. In this study mention about marketing measure or consumer relation measure by dividing into two methods measurements; consumer perception measurement and consumer behavior measurement. Customer perception measurement is when customers satisfied with a business or products, which perceive an overall good perception of that business or products. When consumers' perceptions are good, they will continue purchasing goods from this company. These customers also will avoid spreading disappointing experiences to others. Consumer perceptions are based on feelings. A customer perception measurement is an important tool used by companies that express how well the companies are satisfying customers.

Customer behavior is an essential key to any business. Knowing what the customer wants and how the customer interacts with product designs and marketing. There are many ways, which can measure consumer behavior base on what area you are interested. Normally, conducting market research will allow business to get to know the customers, which mean that business takes customer into account before making business decisions. Resulted in profits on the firm and businesses. Hence, the company necessarily set out goals in conducting marketing activities to create value and improve knowledge and skill to maintain customer and attract new customer. The method to maintain customers is known as Functional method - maintain perception and expectation of brand quality and related services. Perceived sacrifices - is a sacrifice of goods and services to occur short-term or long-term perception such as readers don't receive information in communication channel.

Social Media of PTT Public Company Limited: Social media has influenced in daily life whether Facebook or Twitter. Meanwhile, PTT has researched and developed customer service via social media channel, which can inform as these follows;

\section{Website:}

- www.pttplc.co.th: The center of communication via the internet, the company PTT of informational proposal the overall mission, background of products and services, investor relations, news and also communication with other agencies within the PTT .

- Pttlubricants.pttplc.com :is a website of lubricant product of PTT.

2. Facebook: has fan page and public group manner

- We Love PTT: is responsible to present positive news, both related to the way the PTT and the other offering story content. 
- PTT News: is responsible for the presentation of information and data regards to oil prices and news in the energy sector of PTT.

- PTT Blue Society: is responsible to contact with Blue card customer via phone and website and also update information and PTT Blue card privileges.

- PTT Rayong Academy: is responsible update PTT Rayong football team, their activities with the youth and any information related in football game.

- Tevin at PTT: is a web page of Tevin Vongvanich, CEO of PTT on Facebook to tell the story of work and his visions and perspectives on issues in society and create a closer exchange of information with that web page admin.

- Fellowship of PTT: is a group of public social network in Facebook aims to exchange information and views on energy.

- Jiffy Thailand: is a webpage on Facebook by Jiffy who provides retailing stores as chain stores in PTT, and offer discounts of the shop.

- Café Amazon by PTT is a webpage on Facebook of Café Amazon who provides coffee and beverage; promote activities and discounts of shop for whom follows the webpage.

\section{Twitter:}

- $\quad$ PTTNews proposed channels to inform the headlines and news daily oil price and energy.

- PTT Blue Society is channel of communication with the customer PTT Blue Card and Re-Tweet to receive information on the benefits of the PTT Blue Card .

\section{Line:}

- PTT Group :as a channel of communication with the update application Line connection with the official account will be updated information, news, and information in the field of energy associated with the PTT and who is followed by the official account will receive Godji sticker for free.

\section{YouTube}

- Godji the Adventure :is a cartoon animation of the PTT in the presentation with Godji, which is the company's mascot's stories via you, tube channel.

\section{Application}

- $\quad$ PTT Life Station is an app to search for the nearest gas station or chain stores including updated oil price e.g .LPG and NGV.

- $\quad$ PTT Blue Card is an app as membership card for accumulating points to acquire premium benefits .

- Jiffy shop is an app for presenting promotion products Jiffy or chain stores of PTT .

- PTT 84 Tambon is an app for updated any projects that related to PTT's project 'Environmental Conservation and Improve Human Being in 84 Tambon) sub-district( by sufficiency economy'

- $\quad$ PTT Reforest is apps to update the reforestation project of the PTT .

- $\quad$ PTT -iPocket HD is an app for accounting book contains revenue and expense designed by PTT .

- Amazon Drive Awake is an app searching for the nearest Café Amazon's location.

- PTT Insight is an app that proposes any related of PTT situation comply with understanding analysis .

All of above can be aggregated to Figure 3. 
Figure 3: List of online social networks of PTT Public Company Limited

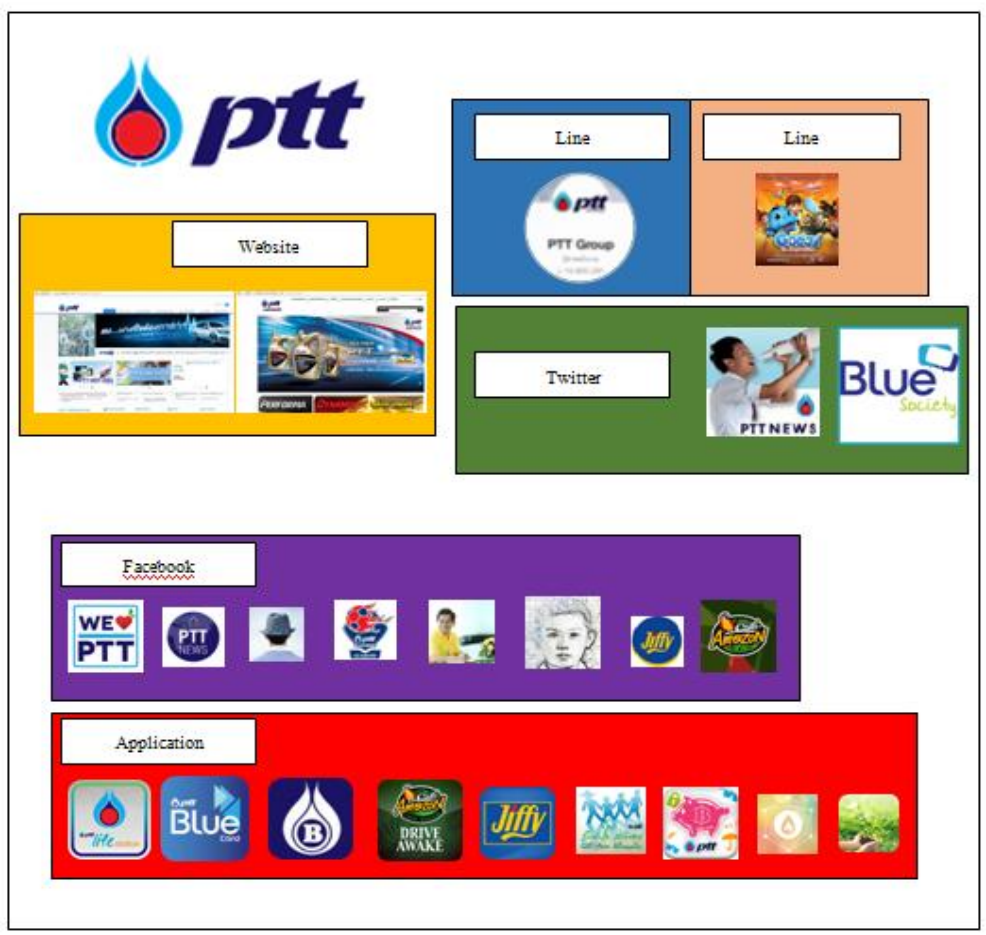

PTT has a lot of social media comparing with other energy companies. Variety channels of social media are used to control, prevent and solve negative result as well as to increase corporate image from investor and public. Likewise, other energy companies also have websites and social media on their own.

Table 1: Comparison of PTT's social media and other energy companies

\begin{tabular}{|c|c|c|c|}
\hline Company Lists & Website & Social Network & Application \\
\hline PTT & 2 Websites & $\begin{array}{l}1 \text { YouTube Channel } \\
2 \text { Twitters Acc. } \\
8 \text { Facebook pages }\end{array}$ & $\begin{array}{l}1 \text { Line } \\
9 \text { Applications }\end{array}$ \\
\hline Bangchak & 1 Website & $\begin{array}{l}2 \text { Facebook pages } \\
1 \text { YouTube Channel } \\
1 \text { Twitter Acc. }\end{array}$ & 1 Application \\
\hline Chevron & 1 Website & $\begin{array}{l}1 \text { YouTube } \\
1 \text { Facebook page }\end{array}$ & \\
\hline Shell & 3 Websites & $\begin{array}{l}1 \text { YouTube } \\
1 \text { Likedln } \\
1 \text { Instagram } \\
1 \text { Facebook }\end{array}$ & 8 Applications \\
\hline
\end{tabular}

\section{Methodology}

This study adopted mix method by using both quantitative and qualitative method as these follows;

Quantitative research: The Quantitative research made by collecting sample of who has been using social media of PTT and age above 18 years old for 400 persons by using convenience sampling from customers' surveying who grateful and willing to cooperate to answer the survey from anyplace. The survey method contains of four sections as below;

- Sect 1 Ethnography Survey

- $\quad$ Sect 2 Survey of usage and access to PTT via social media. 
- Sect 3 Survey of marketing communication to perceive PTT information .

- Sect 4laicoS media affects to communication.

Monitoring query tool with a study and review of documents related research on the impact of Social media, which affected to PTT's customer as a guideline to create survey and valid content. Researcher was verified by supervisor and three experts in order to make content validity, appropriate wording, reliability and reliability to consider statistics of research in this study that using reliability at the rate of 95 percent as criterion to be accepted in this hypothesis by using statistics to analysis data in each segment as follows;

- General data analysis by analyzing the gender, age, status, education, occupation and income average per month .The services that customer used to access to the social media that analyses into number, percentage, general enquiries with frequency and percentage.

- Comparison average score of social media marketing and information perception of PTT within the sample group.

- Mean and Standard Deviation to compare level of awareness of the PTT.

- Inferential statistic including data analysis to examine the relationship between variables and the dependent variable data to test data to test hypotheses and each independent by controlling of other variables and statistical analyses that using binary regression analysis to find the forecasting the impact that derived from social media.

Qualitative Research: Qualitative research collected into 2 groups. One is interviewed by using purposive sampling of customer who has been using service of PTT's social media above the age 18 years old and number of interviewer more than 400 persons. The purpose of study consistent with research question by having open-ended question for 10 sections. The quality of data analysis done from the interview. During the interview researcher has interviewed open-ended and non-directive method. The other is in-depth interview from 5 selective customers by directive method. The researcher has determined the section to analyze and find elements of "Social Media's Perception Affects towards PTT's Customer Services" and divided into periodically accordance with topic or appropriate time. The research will conclude the interview, recorded on a form to be interviewed and listened to suggestions to improve an interview or so-called cumulative summarization technique. The scope of interview analysis as a key component of social media impact towards customer's perception of PTT. Then, it will be analyzed the data analysis.

\section{Conclusion and Recommendations}

The result from Quantitative Research: The positive side, the sampling group commented on positive issues when social media crisis occurred, they always encouraged PTT or informed accurate information and edited information as a fact that happens in the contexts, which some of contents related with PTT were arranged and could response to negative attitude of social media that was advantaged for company's image and creditability as in table 1

Table 1: Social media impact to attitude for PTT product and service

\begin{tabular}{lll}
\hline Impact side & Mean & Result \\
\hline Positive side overall & 3.1792 & Medium \\
Negative side overall & 2.5948 & Medium \\
\hline
\end{tabular}

From table 1, both of Positive and Negative sides were impacted at medium level but in-depth from number of mean. The negative side is nearly small impact. It proved that PTT social media cause negative impact lower than positive, however positive impact could not reach high impact level. This meant PTT should develop their communication to make higher impact. The neutral side, the sampling group in this side has neutral opinion on PTT social media which neither accompany with PTT nor show pessimistic information. It showed that the perception PTT social media did not affect positively or negatively but it could be changed to any side one day. The company should be proactive to manage this group of customer. The negative side, the sampling group in this side was affected by negative message via social media. The contents might be the old issue from previous day by repetition technique. PTT required preventing information and managing social media in various situations to pursuit the negative flow of information and providing the truth for via social 
media. Although PTT has prepared as much social media for their communication as they can e.g. in website, apps, and social network, people selected to perceive only when they would like to know. Although PTT monitored all news content in social media, not much effective strategy came out. Therefore, it is important to find the measurement tools to analyze social media content at the root cause and increase the positive perception, decrease the negative percept and change the neutral side to be positive side. There should be integrated work of legal, public relations, marketing, ICT and event third person to developed appropriate use of social media that contributed to business and image.

\section{References}

Chi, H. (2011). Interactive Digital Advertising VS. Virtual Brand Community: Exploratory Study of User Motivation and Social Media Marketing Responses in Taiwan. Journal of Interactive Advertising, 2, 4461.

Erdogmus, E. I. \& Cicek, M. (2012). The Impact of Social Media Marketing on Brand Loyalty. Social and Behavioral Sciences, 58, 1353 - 1360.

Khuong, N. \& Tram, B. (2015). The Effects of Emotional Marketing on Consumer Product Perception, Brand Awareness and Purchase Decision - A Study in Ho Chi Minh City, Vietnam. Journal of Economics, 3, 524 - 530. Doi: 10.7763/JOEBM.2015.V3.240

Tugrul, O. T. (2014). Brand Experience Effects on Consumers Social Media: Marketing Perception and Brand Value.

Phaisarn, J. (2016). Social Media and Communication for investor relations. SD Focus, 3, 14-15.

Dincer, C. \& Dincer, B. (2012). Social Media Use, Perceptions and Implication. Afyon Kocatepe Üniversitesi, İ̈BF Dergisi.

Banu, K. D. (2015). Relative Importance of Perceived Value, Satisfaction and Perceived Risk on Willingness to Pay More. International Review of Management and Marketing, 5(4), 211-220.

Yun, B. \& Cho, Y. C. (2014). Analyzing the Effectiveness of Public Policy Advertising on Attitudes and Behavioral Changes. Journal of Business \& Economics Research, 4(12), 357 - 370.

Moosa, M. \& Hassan, Z. (2015). Customer Perceived Values associated with Automobile and Brand Loyalty. International Journal of Accounting, 1, 1-16.

Camelia, M. (2012). Impact of Integrated Marketing Communication on Consumer Behaviour: Effects on Consumer Decision - Making Process. International Journal of Marketing Studies, 2(4), 121-129.

Murat, M. Y., Duygu, T. \& Nil, S. E. (2015). Corporate Reputation in the Era of Social Media: A Study in Turkish Banking Industry. The IUP Journal of Business Strategy, 2(6), 28-42. 